\title{
Review Article \\ Ecological Speciation and the Intertidal Snail Littorina saxatilis
}

\author{
Juan Galindo ${ }^{1}$ and John W. Grahame ${ }^{2}$ \\ ${ }^{1}$ Departamento de Bioquímica, Xenética e Inmunoloxía, Facultade de Bioloxía, Universidade de Vigo, \\ Campus de Vigo, 36310 Vigo, Spain \\ ${ }^{2}$ School of Biology, University of Leeds, Leeds LS2 9JT, UK \\ Correspondence should be addressed to John W. Grahame; j.w.grahame@leeds.ac.uk
}

Received 3 April 2014; Revised 18 June 2014; Accepted 19 June 2014; Published 22 July 2014

Academic Editor: Sveinn Are Hanssen

Copyright (C) 2014 J. Galindo and J. W. Grahame. This is an open access article distributed under the Creative Commons Attribution License, which permits unrestricted use, distribution, and reproduction in any medium, provided the original work is properly cited.

In recent decades biologists studying speciation have come to consider that the process does not necessarily require the presence of a geographical barrier. Rather, it now seems to be possible for reproductive barriers to evolve within what was hitherto a single "species." The intertidal snail Littorina saxatilis has been the focus of a considerable amount of work in this context, and it is now thought of as a good case study of "ecological speciation." We review some of this work and briefly consider prospects for future developments.

\section{Introduction}

In recent decades, there has been a considerable shift in our view of speciation-ecology has come in [1]. Or rather, it has come back in because the role of ecological processes in diversification dates back to Darwin, although some biologists of the 20th century gave a prominent role in speciation to geographical isolation (allopatry) $[2,3]$. This shift of view has been reviewed by Mallet [4]. It is our intention here to give an account of work on Littorina saxatilis (Olivi) over the last three decades, highlighting its contribution and promise to the study of speciation.

This marine snail is a species in a small and young genus and is probably the most derived member of the genus Littorina. It is thought to have originated in the eastern North Atlantic about $0.65 \mathrm{Ma}$ bp [5], rapidly colonizing both sides of the Atlantic. Phylogeographic patterns make it likely that more northern populations have undergone repeated subdivision and recontact as shorelines have been subject to glacial action and concomitant sea level changes. Populations on the northwestern coasts of the Iberian Peninsula appear to be genetically distinct from those elsewhere, suggestive of relatively long isolation [5-7]. L. saxatilis is strictly intertidal, though within the intertidal it has a fairly wide vertical distribution, and is found on rocky shores and in estuaries and salt marshes [8]. There are few published data on longevity. Hughes [9] gives a maximum of about four years.

Littorina saxatilis is also highly polymorphic, and this has given rise to a great deal of taxonomic confusion and synonymy. It is part of a species complex, the group of rough periwinkles, with its sister species Littorina compressa (Jeffreys) and Littorina arcana Hannaford Ellis [8]. These latter produce egg masses which are deposited in sheltered crevices on the shore, while $L$. saxatilis females carry their embryos in a brood pouch in the dorsal mantle cavity until they are released as "crawl aways," with similar morphology to the adult snails. Interestingly, there is evidence of hybridization and gene flow between $L$. saxatilis and $L$. arcana [10]. These oviparity and ovoviparity reproductive strategies both favour processes of local adaptation (in contrast with other members of the genus (e.g., Littorina littorea (L.)), which are relatively long-distance dispersers through their planktonic eggs and larvae [11].

One of the current challenges in studying Littorina saxatilis is bringing together phenotypic variation, genetic variation, and ecology, so that coherent conclusions may be drawn. This may be achieved at the local scale by studying the extreme environmental gradients occurring on the tidal shores of north-western Europe, and since about 1980 littorinid biologists have been interested in the relationship 
between the habitat-related phenotypic divergence and the genetic structure of the snail populations. Work along these lines has been carried out in three distinct and geographically separated European locations: the Galician coast of Spain $\left(\sim 43^{\circ} \mathrm{N}\right)$, the east coast of Britain $\left(\sim 55^{\circ} \mathrm{N}\right)$, and the northern Bohuslän coast of Sweden $\left(\sim 58^{\circ} \mathrm{N}\right)$. The distance between these locations is of the order of $4,000 \mathrm{~km}$ with the British location being nearer to the Swedish $(\sim 1,600 \mathrm{~km})$ than the Spanish $(\sim 2,400 \mathrm{~km})$. We now give brief outlines of some studies on these rocky intertidal locations (Figure 1).

\section{Three Principal Study Systems}

The Galician coast of Spain-tidal range is $\sim 3 \mathrm{~m}$ vertically. Studies have taken place on gently sloping granite shores exposed to Atlantic waves. In the upper parts of the study transects, the snails are exposed to predation by the crab Pachygrapsus marmoratus (Fabricius), as well as to relatively long periods of desiccation, while lower down the principal environmental stress is considered to come from wave action. On these shores, conspicuously different ecotypes occur: a relatively large snail with a ridged shell in the upper shore (referred to as "RB", ridged-banded) and a smaller snail with a smooth and larger aperture shell referred to as "SU" (smoothunbanded). Rolán-Alvarez [12] provides photographs of the shore and ecotypes. These ecotypes present empirical evidence of adaptation to their native microhabitat. There is a well-defined hybrid zone in the mid-shore, with individuals of intermediate phenotypes, where all forms survive equally well, while the RB and SU ecotypes survive best in their native environment [13]. Movement rates are low, about 1$3 \mathrm{~m}$ per month, consistent with what is known elsewhere for Littorina (see K. Johannesson and B. Johannesson [14] for a higher estimate of $5 \mathrm{~m}$ per month, perhaps associated with low population densities). If displaced out of zone, both $\mathrm{RB}$ and SU ecotypes tended to migrate back to their native zone, though this was comparatively weak in SU because their movement is even less than that of RB [15]. Male-female pairs from the field showed strong assortative mating both with respect to ecotype and size (large females being preferred by males) though these effects were somewhat blurred in the laboratory [16]. Cruz and García [17] found evidence of reduced fecundity in intermediate females, and the sperm of hybrid males may be less viable due to enhanced DNA fragmentation rates [18]. While a lack of postzygotic isolation was found under laboratory conditions [19], patterns of hybridization across different shores are in support [20]. Thus there is evidence of both pre- and postzygotic barriers to mating between the ecotypes, which nonetheless are too weak to prevent gene flow between them. This system of diverged ecotypes with a hybrid zone between them develops across a shore extent of up to about $60 \mathrm{~m}$ horizontally [12], study transects are within this, typically across $10-24 \mathrm{~m}$ of the shore [21].

The British system-tidal range is $\sim 5 \mathrm{~m}$ vertically, so of the same order as for the Galician system in Spain. The most studied shores are characterised by very gently sloping bedrock with scattered or dense boulders in the mid-shore, with hard bedrock cliffs or large ( $\sim 2$ to $4 \mathrm{~m}$ ) boulders in the higher shore. At several locations along a $66 \mathrm{~km}$ stretch on the Yorkshire coast Hull et al. [22] found that populations on cliffs or large high-shore boulders consisted of snails with thin, relatively large-apertured shells (referred to as " $\mathrm{H}$," highshore), while snails in the mid-shore had much thicker shells with smaller apertures (referred to as "M," mid-shore). The broods of $\mathrm{H}$ snails consisted of fewer and larger embryos, while those of $M$ snails had more and smaller embryos. There were also shells of intermediate form at low frequency; the females of these intermediates had broods consisting of embryos of both sorts and many of them were either grossly abnormal or aborting, which is considered to be a clear indication of hybrid inviability [22]. There was assortative mating by size and ecotype [23]. Pickles and Grahame [24] found that when size was controlled to within $\pm 1 \mathrm{~mm}$ shell length, ecotype-assortative mating occurred both within each of two shores and between the shores, separated by $20 \mathrm{~km}$. There is an obvious contrast with the Galician system in that the ecotype which might be considered to be resistant to wave exposure occurs in the upper shore. The British shores are typically more heterogeneous than those of the study transects in Galicia, and the spatial separation of the ecotypes is of the same order $[23,25]$.

The Swedish system-tidal range is $\sim 0.4 \mathrm{~m}$. This presents an environmental contrast to the previous two systems; the phenotypic cline occurs along the coast between waveprotected boulders in bays and wave-exposed promontories; these habitats are sometimes separated by as little as $10 \mathrm{~m}$ [26]. On the promontories an "E" (exposed) ecotype is found, with a thin shell and large aperture, contrasted with an "S" (sheltered) ecotype in the bays. There are large populations of an intermediate "I" ecotype between them in a transition habitat. Reciprocal transplant experiments showed the ecotypes to survive better in their native habitat, including "I" in the intermediate habitat. A contrast with the previous systems is that the intermediate phenotypes represent a greater fraction of the total population, reflecting the larger intermediate habitat in the Swedish system. Overall movement rates were low, of the order of $1 \mathrm{~m}$ per month, which would be enough to homogenize the populations if at least some degree of habitat choice was not present. The broods of the ecotypes were in accordance with those reported for the British system, including some evidence of hybrid inviability [27]. Assortative mating between the ecotypes was found, and it is independent of geography [28]. In this system it has also been reported that males discriminate ecotypes from the mucous trail of a female; this is likely to contribute to assortative mating [29]. A unique attribute of the Swedish system, of the three noted here, is the presence of the habitats in numerous islands of various sizes, separated by sufficient distance that migration of $L$. saxatilis between them must be only very occasional. This has consequences for the genetic substructuring of the snail populations at a very small scale [30].

In all three systems it is clear that the animals can move, and if displaced from their native habitat will attempt, at least to some degree, to migrate back to it. There is published evidence for this for Galicia [15] and for 


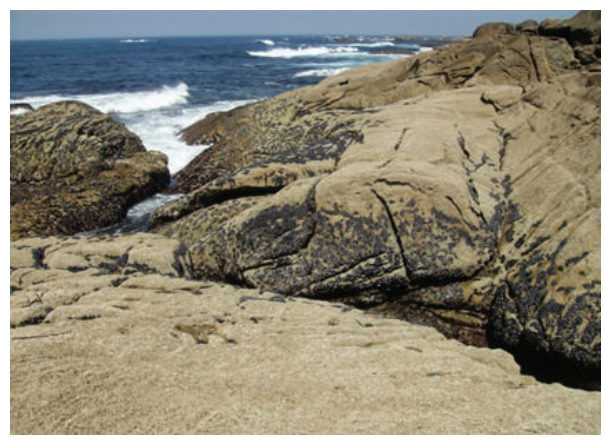

(a)

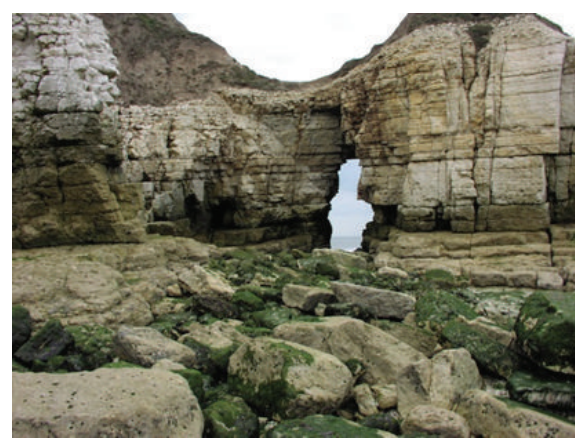

(b)

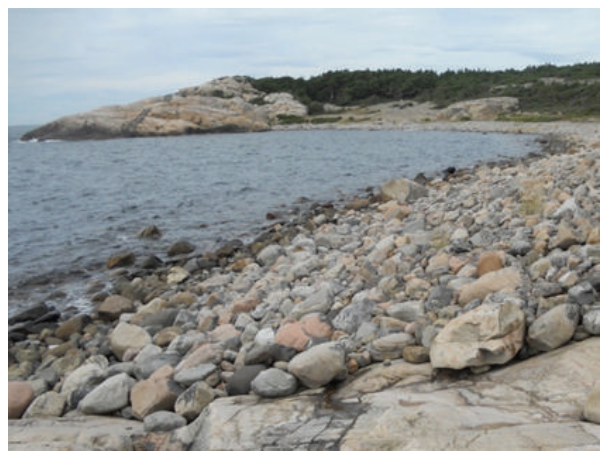

(c)

FIgURE 1: Example shores for the three systems. (a) The Galician shore at Cape Silleiro: the photograph looks down the shore from the RB habitat. (b) The British shore at Thornwick Bay: the H habitat is the near-vertical cliff and the M habitat the boulder field below. (c) The Swedish shore at Saltö: the S habitat is the foreground boulders and the E habitat the promontory beyond the bay. The abbreviations for the ecotypes (RB, etc.) are explained in the text.

Sweden [26], and unpublished evidence for the British system [31]. In the absence of displacement, whether experimental or by natural events, the snails may be rather sedentary. Atkinson and Newbury [32] inferred that the small but significant size differences of snails on different surfaces of causeway pillars meant that the snails largely remained on one side of the pillar and were very locally adapted.

\section{Do the Ecotypes Represent a Stage in Speciation?}

From early on in the studies cited above, authors were considering the possible implications of the phenotypic variation in terms of speciation. With the evidence for gene flow between the ecotypes in each system they were all considered to belong to one species, namely, L. saxatilis. Given the high fitness of hybrids (in their habitat) and the smooth transition between the extreme ecotypes in the Swedish system it was considered unlikely that this represented a situation in which reproductive isolation might arise $[33,34]$, and see Sadedin et al. [35]. A more likely candidate system for the evolution of isolation might be the Galician ecotypes, which show greater genetic differentiation on average [7]. Here, habitat selection, assortative mating, and perhaps sexual selection by females all were considered to contribute to partial reproductive isolation between the RB and SU morphs [36]. It was argued, based on genetic data (e.g., microsatellites, mtDNA, and AFLPs), that the different clines on different shores were of primary origin, rather than secondary, and so representing a case of sympatric speciation [20, 37-39].

Investigations designed to detect DNA loci possibly under selection were also informative. Using amplified fragment length polymorphisms (AFLP) methodology to conduct a genome scan, Wilding et al. [25] showed that there were indeed potential candidate loci under selection and that there was an interesting pattern when selected versus putatively neutral loci were considered (Figure 2).

Figure 2(a) shows the ecotypes grouping together, presumably reflecting the similarity of selection-driven outcomes in the four sets of populations. Figure 2(b) shows the ecotypes grouping by shore and irrespective of ecotype; this tree is based on the nondifferentiating loci and represents presumably drift-driven patterns of similarity. It suggests that now the shores are relatively independent of one another, with little gene flow between them. However, this is a recent snapshot and tells us nothing about the history of the populations - the differentiation could have arisen in allopatry, a plausible explanation given the environmental perturbations of glacial events.

An AFLP genome scan in Galician L. saxatilis gave a strikingly similar sort of pattern [20] (see Figure 3). Here the 


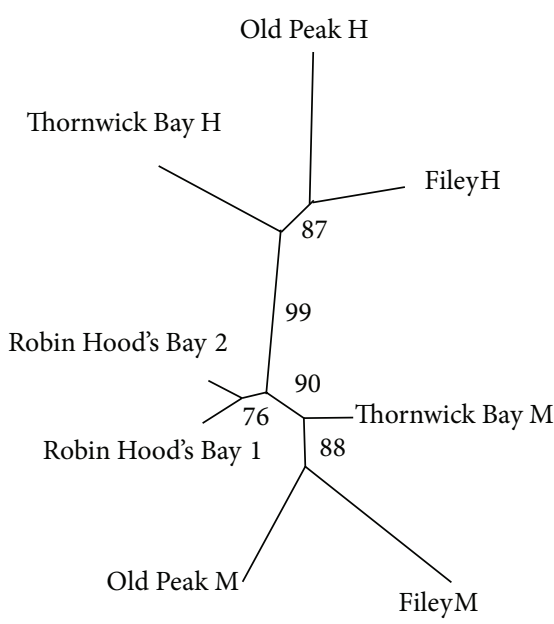

0.01

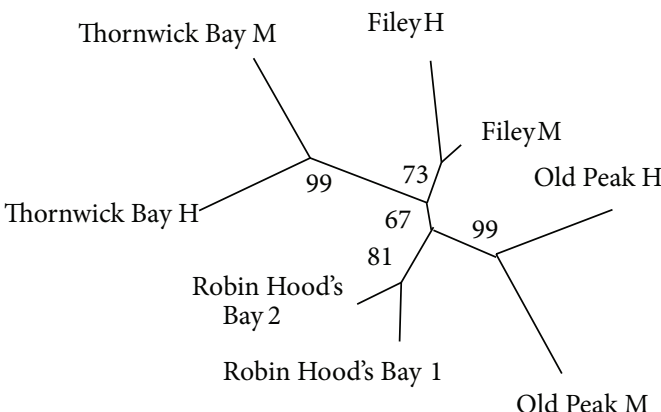

0.01
All loci

(a)
15 "selected" loci removed

(b)

FIGURE 2: The two ecotypes $\mathrm{H}$ and $\mathrm{M}$ on three Yorkshire shores group by ecotype (a) when the loci under selection are included in a neighbourjoining tree using Nei's genetic distance, but by shore when those 15 (out of 290) loci are excluded from the analysis. One shore (Robin Hood's Bay) has only the $\mathrm{M}$ ecotype, and here there are two samples, separated by $75 \mathrm{~m}$ on the shore. The other three shores have both ecotypes separated by $5 \mathrm{~m}$ (Thornwick Bay), $15 \mathrm{~m}$ (Filey), and $300 \mathrm{~m}$ (Old Peak). Bootstrap values are shown on the tree. The shores are along a $45 \mathrm{~km}$ stretch of coast (redrawn from Wilding et al. [25]).

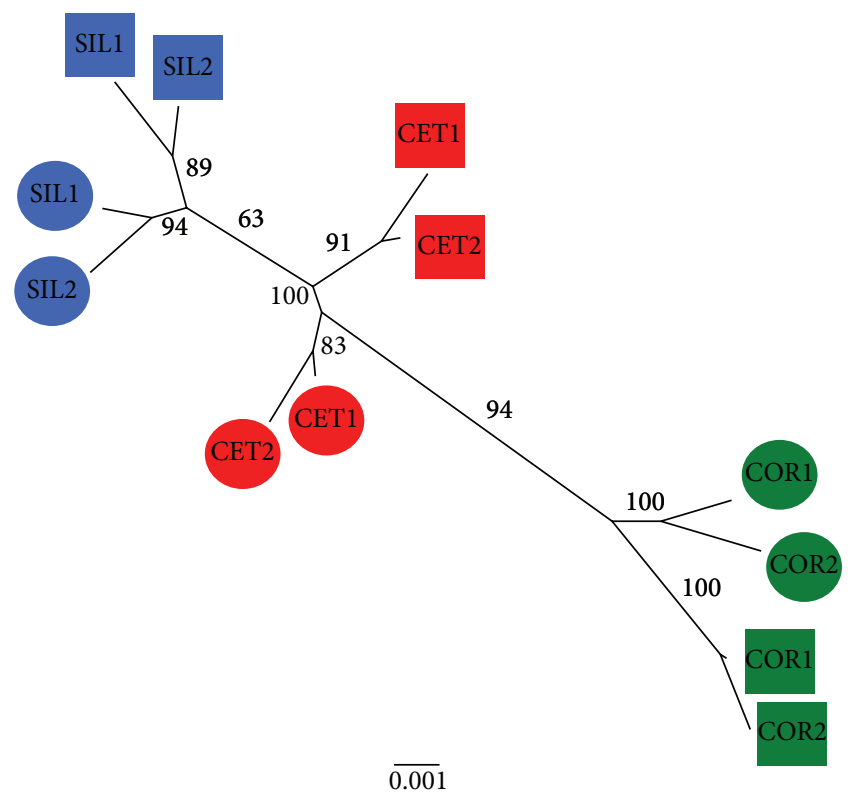

(a) Nonoutlier (1598 loci)

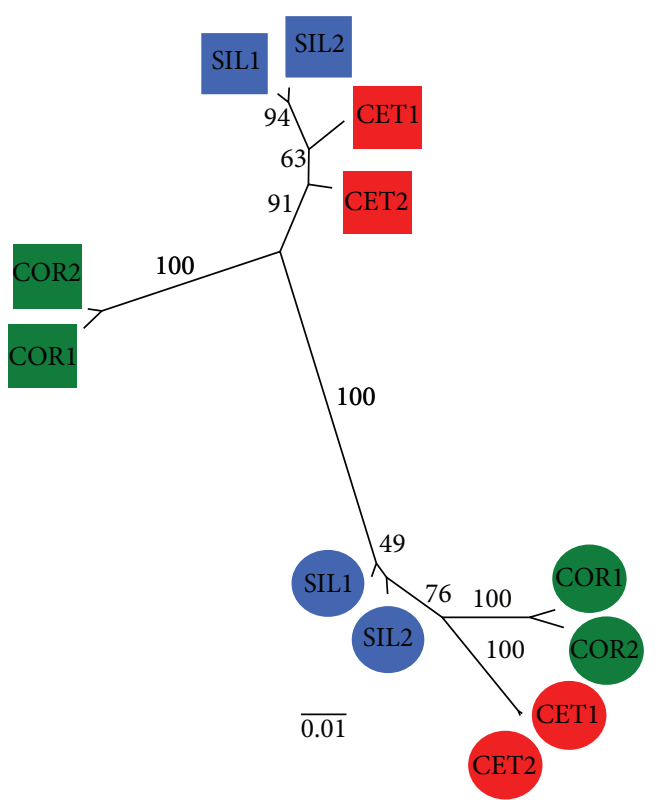

(b) Outlier (92 loci)

FIGURE 3: Neighbour-joining tree using Nei's genetic distance for Galician populations. Bootstrap values (\%) are shown on the trees. The RB (circles) and SU (squares) ecotypes group by shore (Corrubedo, green; Silleiro, blue; Cetarea, red) when nonoutlier loci are used, but by ecotype and then shore when outlier loci are used (redrawn from Galindo et al. [20]).

availability of replicate transects allowed a second level of resolution, showing that some signal between adjacent shores remained even with selected loci.

Similar considerations apply with the Swedish system [30] based on microsatellite neutral variation, with ecotypes grouping within islands, a signature of genetic drift between islands.

In all three systems the variation between the two extreme ecotypes appears to be clinal. Grahame et al. [40] explored this cline on two of the British shores using shell shape and 


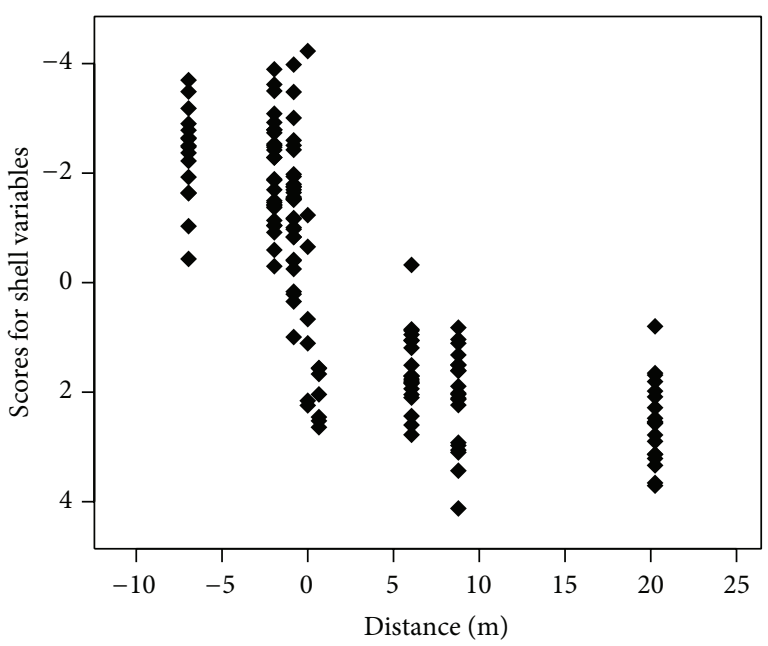

(a)

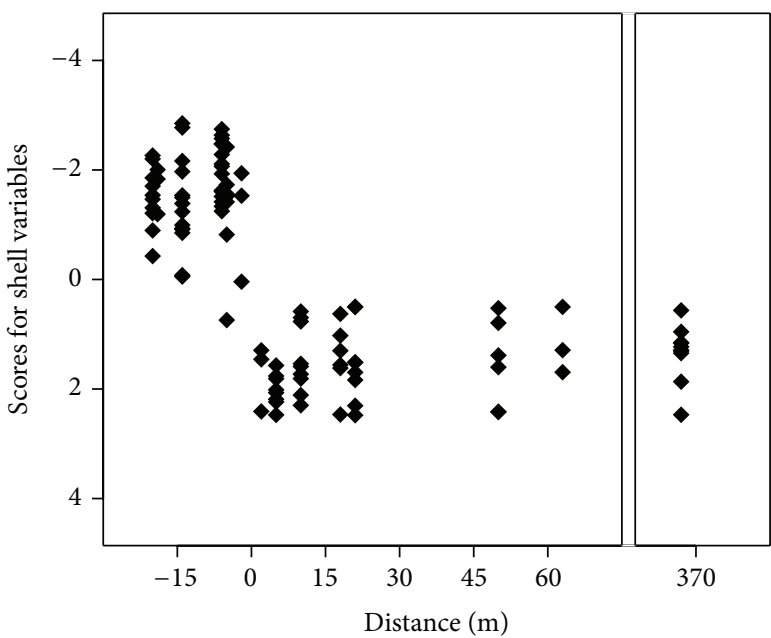

(c)

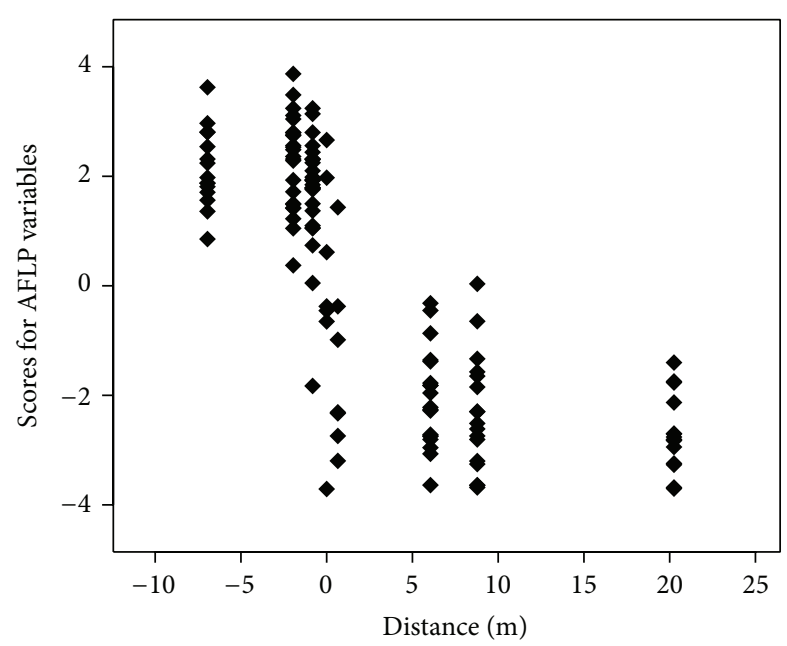

(b)

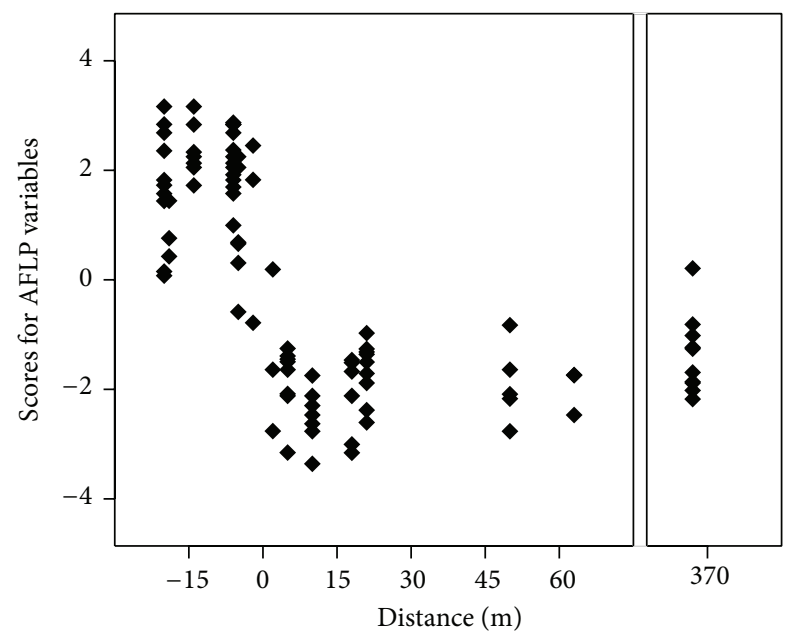

(d)

FIGURE 4: Scores for individual snails plotted on the first canonical variate using shell shape (a, c) and 15 differentiating AFLP bands (b, d) on two shores on the Yorkshire coast, separated by $40 \mathrm{~km}$. The 0 point on the abscissa is chosen so that $\mathrm{H}$ samples are at negative distances, $\mathrm{M}$ at positive, with respect to 0 . This was judged to be the most satisfactory way of representing a somewhat complicated sample layout dictated by the details of shore topography (see Grahame et al. [40] for details).

AFLP. These variables reveal a sharp and correlated cline between $\mathrm{H}$ and $\mathrm{M}$ on these shores (Figure 4) which appears to be independent of the spatial scale difference between them. Similarly, a correlation between phenotype and genotype for candidate loci under selection was found in Galicia, although the spatial scale and ecology played an important role in the clinal variation [20]. The form and congruence (with phenotype and genotype coinciding) of the clines suggested that strong selection must be operating, but apart from the inference of crab predation there is as yet no clear statement of what this selection actually is.

The cline in the British system is evidently very sharp; Grahame et al. [40] considered that it must be maintained by a combination of strong selection and habitat choice.

What does the evidence add up to? The partial reproductive isolation, phenotypic differences coincident with genetic differences, clines along the steep environmental gradients, and repeated occurrence of similar patterns of diversification on different shores may reflect a stage in speciation between these ecotypes. However, in the absence of solid information on the history of the systems, these suggestions remain vulnerable to the criticisms surrounding the inference of evolutionary processes from genetic patterns [40-42].

\section{Apparently the Ecotypes Have Originated Independently}

Until very recently no single study has analysed the three systems simultaneously. Butlin et al. [7] studied, phenotypically and genetically, the ecotypes from Galicia, Britain, and Sweden, including two shores per region. They found remarkably consistent phenotypic divergence between the shells of the ecotypes across regions (Figure 5). Greatest divergence 


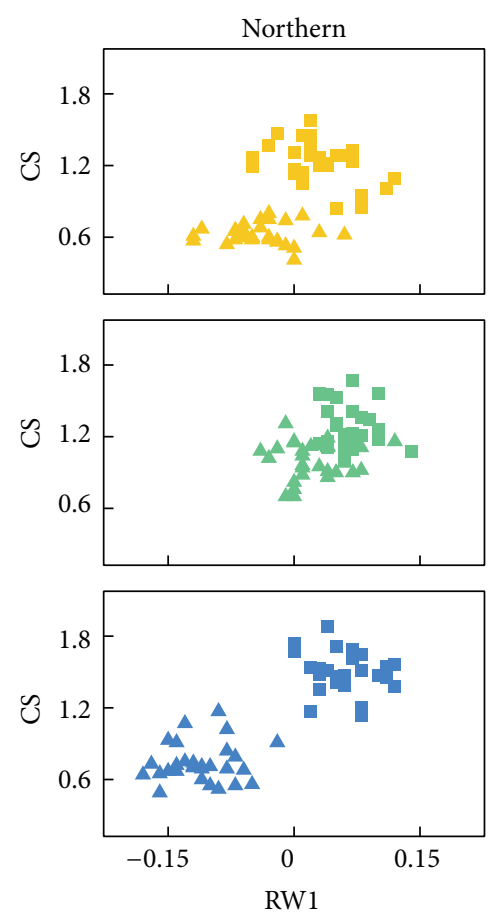

(a)

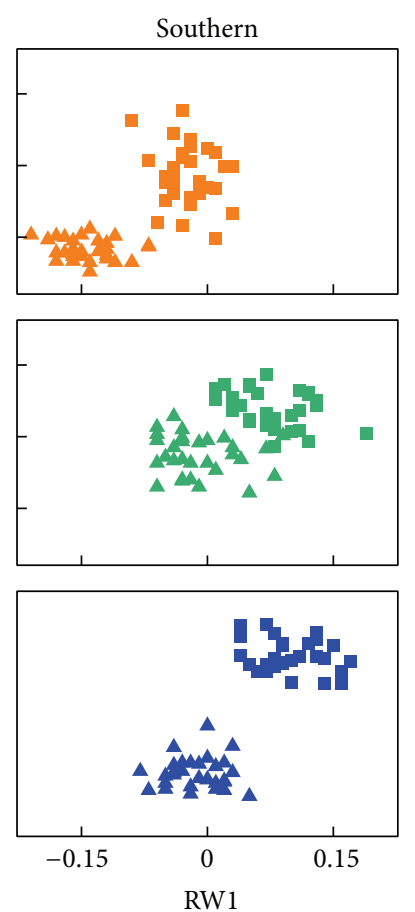

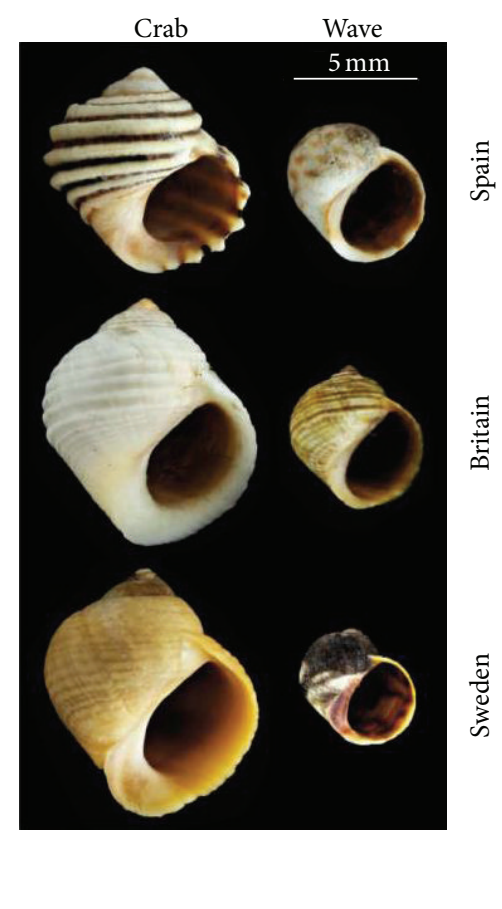

(b)

FIGURE 5: (a) Shape analysis using geometric morphometrics separates the crab and wave ecotypes to varying degrees in the three regions; (b) example shells to illustrate the range of form in these samples (taken from Butlin et al. [7]). The $y$ axis represents the centroid size (CS) and the $x$ axis the most important axis of shape variation (RW1).

was found for Swedish shells and lowest for the "northern" location in Britain. In each region the ecotype referred to here as "wave" is smaller, with a thinner shell, and larger aperture; the "crab" ecotype is larger, with a relatively smaller aperture, and with an evidently thicker shell. The shape analysis here is a "geometric morphometric" one, following the protocol of Conde-Padín et al. [43].

The genetic analysis presented by Butlin et al. consisting of both sequence data and AFLP data was used to test models of demographic history by means of approximate Bayesian computation (see [7] for details). The models best fitting the observed data supported the hypothesis of independent origin of the ecotypes both in the localities (northern, southern) and in the regions (Sweden, Britain, and Galicia). The evidence discussed here points towards the evolution of the ecotypes and their differentiation after the colonization of the shores; it is supposed that this lag may have come about because of environmental limitations on the crab predators, which are both species with warmer preferences than is $L$. saxatilis [7]. Further study of the loci putatively involved in the adaptations, and consideration of some of the other species in the rough periwinkle group, may allow a better understanding of the evolution and diversification of this group.

\section{What Genes Might Be Involved?}

While the repeated emergence of broadly the same loci as outliers in AFLP genome scans across shores in the British system suggests a robust finding, with type I errors in mind it might be considered troubling that in this study the proportion is about $5 \%$ of loci. To investigate some of the loci identified in the British system further, Wood et al. [44] used a bacterial artificial chromosome library to investigate four loci of varying levels of differentiation (maximal to undifferentiated).

Using sequence data, the divergence patterns found were consistent with the patterns found for AFLP loci (Figure 6). This provides further evidence of ecotype divergence in these genomic regions (but see above for caveats in interpreting this in terms of speciation processes). Another interesting question, highly debated, is the size of these genomic regions. Differentiation was found to decline very quickly (a few kilobases) on either side of the DNA sequence that represented a differentiated AFLP locus; thus it was concluded that the genomic regions identified as differentiated were small. For the most differentiated locus (E10, Figure 6(a)) it was suggested that the differentiation was in fact due to the recent insertion of a transposable element which was beneficial in one habitat and not the other. This study, then, did not identify possible candidate coding genes involved in the differentiation of $\mathrm{H}$ and $\mathrm{M}$ ecotypes.

There has been progress here using next generation sequencing to perform a transcriptome scan [45] which has identified putatively selected genes including skeletal matrix proteins (shell formation), skeletal muscle proteins (adhesion and locomotion in a wave-swept environment), and energetic 


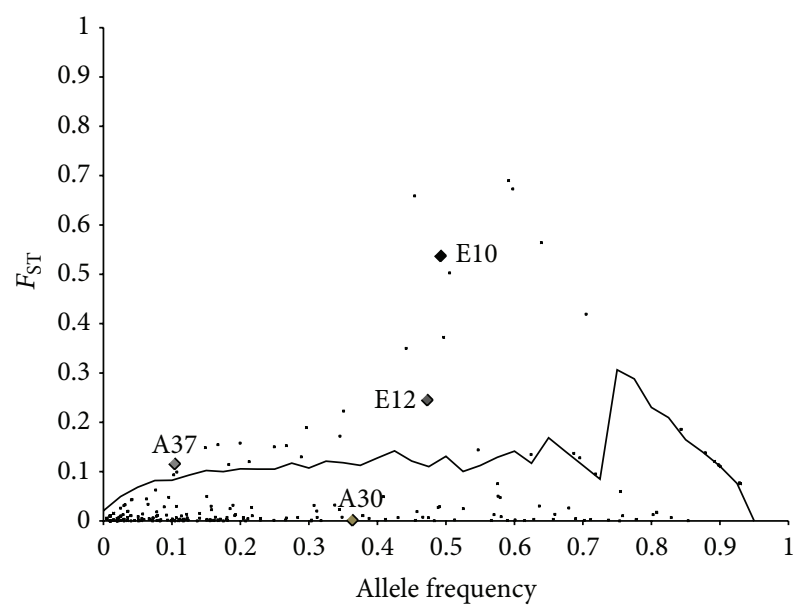

(a)

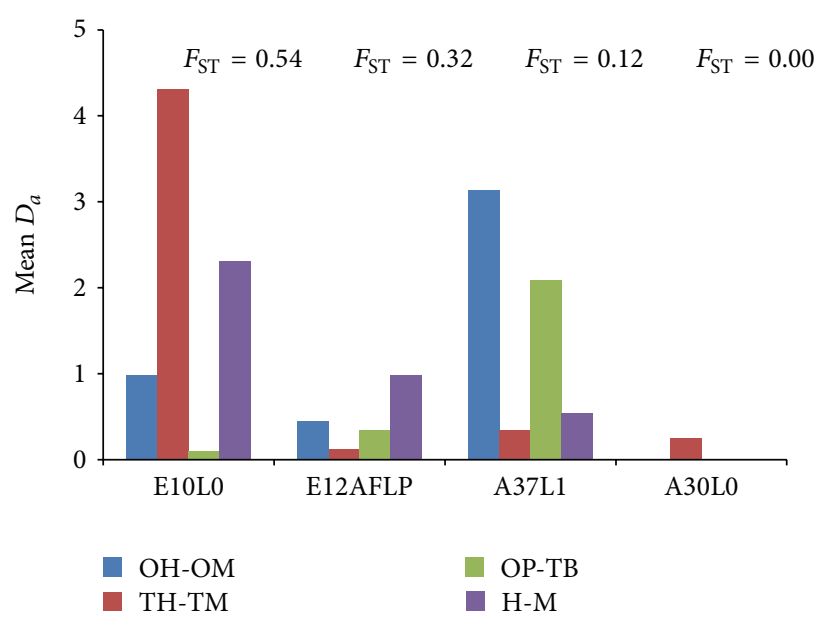

(b)

Figure 6: (a) Differentiated loci in the AFLP genome scan lie above the line for the 0.99 quantile of the simulation model used by Wilding et al. [25]. This is for one shore (Thornwick); 15 of the differentiated loci here were shared across the other two shores. (b) Sequence divergence between samples estimated by $D_{a} ; F_{\mathrm{ST}}$ values come from Wilding et al. [25], and the loci investigated are shown on (a). Shores are Old Peak $(\mathrm{O})$ and Thornwick Bay $(\mathrm{T})$, ecotypes high-shore $(\mathrm{H})$ and mid-shore $(\mathrm{M})$. Thus for each locus, four different divergence estimates are shown: between ecotypes on a shore (OH-OM, TH-TM), an overall site comparison (OP-TB), and an overall ecotype comparison (H-M). (a) Redrawn from Wilding et al. [25]; (b) redrawn from Wood et al. [44].

metabolism as well as possibly reverse transcriptases, indicating again that transposable elements may be important.

\section{Prospects: Crab and Wave and Other Agents of Selection}

Butlin et al. [7] use the terms crab ecotype and wave ecotype, aiming to simplify the names used in the original studies when the ecotypes were described for the first time: "S" (sheltered) and "E" (exposed) in Sweden [46], "M" (mid), and " $\mathrm{H}$ " (high) in Britain [22], and "RB" (ridged-banded) and "SU" (smooth-unbanded) in Spain [21]. Crab and wave denote the main selection forces in their native habitat, although it is not clear whether these are the main drivers of the divergence. Reciprocal transplant experiments test for survival in one habitat, but many selective pressures could be acting, and this is normally not tested. Also, these pressures could all point to a similar phenotype (but maybe different genes); this scenario is difficult to differentiate because by testing only one of these selection forces it is possible to get the expected response, although misleading, because only one force is assumed. Therefore, more ecological studies are needed to test for multiple forces of selection but also genomic studies supporting this hypothesis are necessary.

For example, Walker and Grahame [47] have shown that in the wave ecotype (" $\mathrm{H}$ ") within the British system there is a continuum of shell shape variation. This suggests different axes of shell shape variation in this ecotype. One of these axes of variation was associated with an increase in the relative mass of the brood carried by the female (used as a proxy for reproductive effort) at the expense of the size (mass) of the body (Figure 7). This opens a new line of investigation into the evolution of phenotype variation in L. saxatilis, since there are such clear selection pressures likely to be involved.

Further variation has been found on a shore in south-west Scotland in this same ecotype; a rare mitochondrial haplotype was associated with specific shell shape variation along a continuum of variation [48]. The mechanisms involved in this apparent sequestration of this rare haplotype are unknown. Thus we have two rather widely separated instances of intraecotype variation which seem worthy of further attention.

\section{Conclusion}

A lot has changed in the study of speciation in recent decades, and gene flow and divergent natural selection are important components of key recent studies on the evolution of reproductive isolation [1]. A lot has changed in the study of Littorina saxatilis as well, and a major theme is the contribution of investigations on Littorina to the advances in ecological speciation research [49]. Butlin et al. [7] concluded that the evidence available points to independent parallel evolution of ecotypes adapted to different habitats on the rocky shores studied, with the ecotypes (and associated partial reproductive barriers) arising some time after the colonization of the shores by Littorina saxatilis. The parallel evolution of reproductive barriers in response to similar ecological processes denotes a role for natural selection in speciation as has been shown in other well-known examples of ecological speciation, for example, Timema walking sticks [50].

Therefore it seems that this is a very promising system in evolutionary biology. Littorina has much more potential, still unexplored. Other axes of selection and phenotypic variation in $L$. saxatilis need to be studied in the same detail 


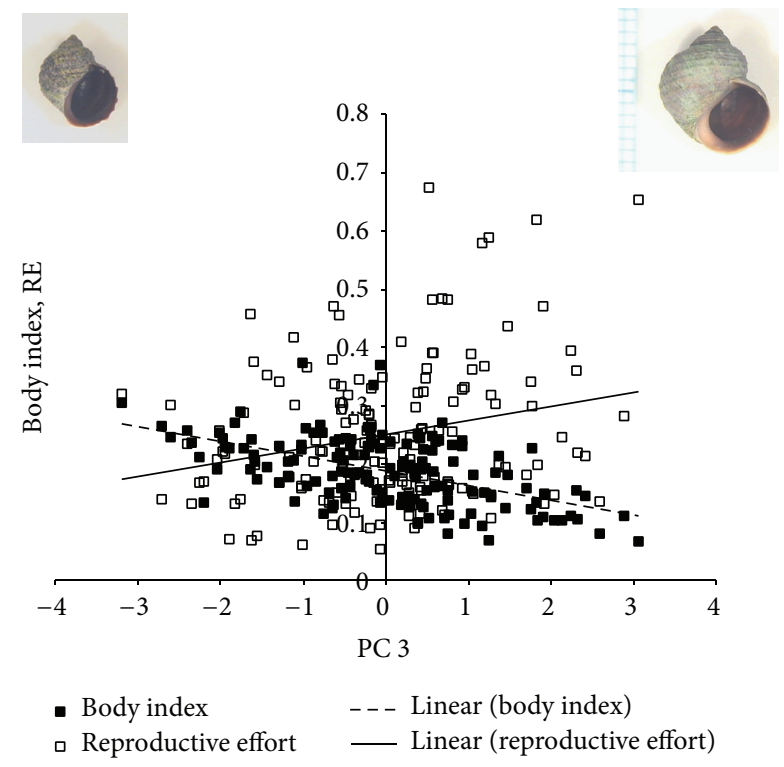

FIGURE 7: Variation in body index (body mass standardised by shell mass) and reproductive effort (brood mass standardised by body mass). The change in shape along principal component three in this analysis is shown with two example shells. There is also a change in size (redrawn from Walker and Grahame [47]).

as the "crab" and "wave" ecotypes, for example, the ecotype "neglecta" [51], as yet comparatively poorly known. Also other closely related species (L. compressa, L. arcana) show important ecological variation [8]. Littorina is a rich resource for the further investigation of intra- and interspecific variation linked to the study of speciation as a continuum [1], from population divergence to species formation.

\section{Conflict of Interests}

The authors declare that there is no conflict of interests regarding the publication of this paper.

\section{Acknowledgments}

The authors thank Roger Butlin for commenting on an earlier draft of this paper and are grateful for the comments of an anonymous referee. Juan Galindo is currently supported by an "Isidro Parga Pondal" fellowship (Xunta de Galicia).

\section{References}

[1] P. Nosil, Ecological Speciation, OUP Oxford, Oxford, UK, 2012.

[2] E. Mayr, "Darwins principle of divergence," Journal of the History of Biology, vol. 25, pp. 343-359, 1992.

[3] D. Schluter and G. L. Conte, "Genetics and ecological speciation," Proceedings of the National Academy of Sciences of the United States of America, vol. 106, pp. 9955-9962, 2009.

[4] J. Mallet, "Why was Darwin's view of species rejected by twentieth century biologists?" Biology \& Philosophy, vol. 25, no. 4, pp. 497-527, 2010.
[5] M. M. Doellman, G. C. Trussell, J. W. Grahame, and S. V. Vollmer, "Phylogeographic analysis reveals a deep lineage split within North Atlantic Littorina saxatilis," Proceedings of the Royal Society: Biological Sciences, vol. 278, no. 1722, pp. 31753183, 2011.

[6] M. Panova, A. M. Blakeslee, A. W. Miller et al., "Glacial history of the North Atlantic marine snail, Littorina saxatilis, inferred from distribution of mitochondrial DNA lineages," PLOS ONE, vol. 6, no. 3, Article ID e17511, 2011.

[7] R. K. Butlin, M. Saura, G. Charrier et al., "Parallel evolution of local adaptation and reproductive isolation in the face of gene flow," Evolution, vol. 68, no. 4, pp. 935-949, 2014.

[8] D. G. Reid, Systematics and Evolution of Littorina, The Ray Society, Dorchester, Mass, USA, 1996.

[9] R. N. Hughes, "Resource allocation, demography and the radiation of life histories in rough periwinkles (Gastropoda)," Hydrobiologia, vol. 309, pp. 1-14, 1995.

[10] N. A. Mikhailova, Y. A. Gracheva, T. Backeljau, and A. I. Granovitch, "A potential species-specific molecular marker suggests interspecific hybridization between sibling species Littorina arcana and L. saxatilis (Mollusca, Caenogastropoda) in natural populations," Genetica, vol. 137, no. 3, pp. 333-340, 2009.

[11] K. Janson, "Allozyme and shell variation in two marine snails (Littorina, Prosobranchia) with different dispersal abilities," Biological Journal of the Linnean Society, vol. 30, no. 3, pp. 245256, 1987.

[12] E. Rolán-Alvarez, "Sympatric speciation as a by-product of ecological adaptation in the Galician Littorina saxatilis hybrid zone," Journal of Molluscan Studies , vol. 73, no. 1, pp. 1-10, 2007.

[13] E. Rolán-Alvarez, K. Johannesson, and J. Erlandsson, "The maintenance of a cline in the marine snail Littorina saxatilis: the role of home site advantage and hybrid fitness," Evolution, vol. 51, no. 6, pp. 1836-1847, 1997.

[14] K. Johannesson and B. Johannesson, "Dispersal and population expansion in a direct developing Marine Snail (Littorina saxatilis) following a severe population bottleneck," Hydrobiologia, vol. 309, no. 1, pp. 173-180, 1995.

[15] J. Erlandsson, E. Rolán-Alvarez, and K. Johannesson, "Migratory differences between ecotypes of the snail Littorina saxatilis on Galician Rocky shores," Evolutionary Ecology, vol. 12, no. 8, pp. 913-924, 1998.

[16] E. Rolán-Alvarez, J. Erlandsson, K. Johannesson, and R. Cruz, "Mechanisms of incomplete prezygotic reproductive isolation in an intertidal snail: testing behavioural models in wild populations," Journal of Evolutionary Biology, vol. 12, no. 5, pp. 879-890, 1999.

[17] R. Cruz and C. García, "Disruptive selection on female reproductive characters in a hybrid zone of Littorina saxatilis," Evolutionary Ecology, vol. 15, no. 3, pp. 167-182, 2001.

[18] A. Sá-Pinto, M. Martínez-Fernández, C. López-Fernánde et al., "Incipient post-zygotic barrier in a model system of ecological speciation with gene flow," Journal of Evolutionary Biology, vol. 26, no. 12, pp. 2750-2756, 2013.

[19] M. Saura, M. Martínez-Fernández, M. A. Rivas, A. Caballero, and E. Rolán-Alvarez, "Lack of early laboratory postzygotic reproductive isolation between two ecotypes of Littorina saxatilis (Mollusca, Gastropoda) showing strong premating sexual isolation," Hydrobiologia, vol. 675, no. 1, pp. 13-18, 2011.

[20] J. Galindo, M. Martínez-Fernández, S. T. Rodríguez-Ramilo, and E. Rolán-Alvarez, "The role of local ecology during 
hybridization at the initial stages of ecological speciation in a marine snail," Journal of Evolutionary Biology, vol. 26, no. 7, pp. 1472-1487, 2013.

[21] K. Johannesson, B. Johannesson, and E. Rolán-Alvarez, "Morphological differentiation and genetic cohesiveness over a microenvironmental gradient in the marine snail Littorina saxatilis," Evolution, vol. 47, no. 6, pp. 1770-1787, 1993.

[22] S. L. Hull, J. Grahame, and P. J. Mill, "Morphological divergence and evidence for reproductive isolation in Littorina saxatilis (Olivi) in northeast England," Journal of Molluscan Studies, vol. 62, pp. 89-99, 1996.

[23] S. L. Hull, "Assortative mating between two morphs of Littorina saxatilis on a shore in Yorkshire," Hydrobiologia, vol. 378, pp. 79-88, 1998.

[24] A. Pickles and J. Grahame, "Mate choice in divergent morphs of Littorina saxatilis (olivi): speciation in action?" Animal Behaviour, vol. 58, pp. 181-184, 1999.

[25] C. S. Wilding, R. K. Butlin, and J. Grahame, "Differential gene exchange between parapatric morphs of Littorina saxatilis detected using AFLP markers," Journal of Evolutionary Biology, vol. 14, no. 4, pp. 611-619, 2001.

[26] K. Janson, "Selection and migration in two distinct phenotypes of Littorina saxatilis in Sweden," Oecologia, vol. 59, pp. 58-61, 1983.

[27] K. Janson, "Variation in the occurrence of abnormal embryos in females of the intertidal gastropod Littorina saxatilis Olivi," Journal of Molluscan Studies, vol. 51, pp. 64-68, 1985.

[28] J. Hollander, M. Lindegarth, and K. Johannesson, "Local adaptation but not geographical separation promotes assortative mating in a snail," Animal Behaviour, vol. 70, no. 5, pp. 12091219, 2005.

[29] K. Johannesson, J. N. Havenhand, P. R. Jonsson, M. Lindegarth, A. Sundin, and J. Hollander, "Male discrimination of female mucous trails permits assortative mating," Evolution, vol. 62, no. 12, pp. 3178-3184, 2008.

[30] M. Panova, J. Hollander, and K. Johannesson, "Site-specific genetic divergence in parallel hybrid zones suggests nonallopatric evolution of reproductive barriers," Molecular Ecology, vol. 15, no. 13, pp. 4021-4031, 2006.

[31] S. E. Webster, Selection for local adaptation in Littorina saxatilis, The University of Sheffield, Sheffield, UK, 2014.

[32] W. D. Atkinson and S. F. Newbury, "The adaptations of the rough winkle, Littorina rudis, to desiccation and dislodgement by wind and waves," Journal of Animal Ecology, vol. 53, pp. 93$105,1984$.

[33] K. Janson and P. Sundberg, "Multivariate morphometric analysis of two varieties of Littorina saxatilis from the Swedish West Coast," Marine Biology, vol. 74, pp. 49-53, 1983.

[34] K. Johannesson and P. Sundberg, "Speciation in Littorina saxatilis (Olivi)? - a one-dimensional selection-migration model," in Proceedings of the 3rd International Symposium on Littorinid Biology, J. Grahame, P. J. Mill, and D. G. Reid, Eds., pp. 1-8, The Malacological Society, London, UK, 1992.

[35] S. Sadedin, J. Hollander, M. Panova, K. Johannesson, and S. Gavrilets, "Case studies and mathematical models of ecological speciation. 3: ecotype formation in a swedish snail," Molecular Ecology, vol. 18, no. 19, pp. 4006-4023, 2009.

[36] K. Johannesson, E. Rolán-Alvarez, and A. Ekendahl, "Incipient reproductive isolation between two sympatric morphs of the intertidal snail Littorina saxatilis," Evolution, vol. 49, pp. 11801190, 1995.
[37] E. Rolán-Alvarez, M. Carballo, J. Galindo et al., "Nonallopatric and parallel origin of local reproductive barriers between two snail ecotypes," Molecular Ecology, vol. 13, no. 11, pp. 3415-3424, 2004.

[38] H. Quesada, D. Posada, A. Caballero, P. Morán, and E. RolánAlvarez, "Phylogenetic evidence formultiple sympatric ecological diversification in a marine snail," Evolution, vol. 61, no. 7, pp. 1600-1612, 2007.

[39] J. Galindo, P. Morán, and E. Rolán-Alvarez, "Comparing geographical genetic differentiation between candidate and noncandidate loci for adaptation strengthens support for parallel ecological divergence in the marine snail Littorina saxatilis," Molecular Ecology, vol. 18, no. 5, pp. 919-930, 2009.

[40] J. W. Grahame, C. S. Wilding, and R. K. Butlin, "Adaptation to a steep environmental gradient and an associated barrier to gene exchange in Littorina saxatilis," Evolution, vol. 60, no. 2, pp. $268-$ 278, 2006.

[41] N. Bierne, J. Welch, E. Loire, F. Bonhomme, and P. David, "The coupling hypothesis: why genome scans may fail to map local adaptation genes," Molecular Ecology, vol. 20, no. 10, pp. 20442072, 2011.

[42] N. Bierne, P. A. Gagnaire, and P. David, "The geography of introgression in a patchy environment and the thorn in the side of ecological speciation," Current Zoology, vol. 59, no. 1, pp. 7286, 2013.

[43] P. Conde-Padín, A. Caballero, and E. Rolán-Alvarez, "Relative role of genetic determination and plastic response during ontogeny for shell-shape traits subjected to diversifying selection," Evolution, vol. 63, no. 5, pp. 1356-1363, 2009.

[44] H. M. Wood, J. W. Grahame, S. Humphray, J. Rogers, and R. K. Butlin, "Sequence differentiation in regions identified by a genome scan for local adaptation," Molecular Ecology, vol. 17, no. 13, pp. 3123-3135, 2008.

[45] J. Galindo, J. W. Grahame, and R. K. Butlin, "An EST-based genome scan using 454 sequencing in the marine snail Littorina saxatilis," Journal of Evolutionary Biology, vol. 23, no. 9, pp. 2004-2016, 2010.

[46] K. Janson, "Phenotypic differentiation in Littorina saxatilis Olivi (Mollusca, Prosobranchia) in a small area on the Swedish West Coast," Journal of Molluscan Studies, vol. 48, pp. 167-173, 1982.

[47] T. N. Walker and J. W. Grahame, "Shell shape variation and fitness variables in the gastropod Littorina saxatilis," Marine Ecology Progress Series, vol. 430, pp. 103-111, 2011.

[48] N. A. M. Chrismas, B. Torres-Fabila, C. S. Wilding, and J. W. Grahame, "An association of mitochondrial haplotype with shell shape in the intertidal gastropod Littorina saxatilis," Journal of Molluscan Studies, vol. 80, no. 2, pp. 184-189, 2014.

[49] R. Faria, S. Renaut, J. Galindo et al., "Advances in ecological speciation: an integrative approach," Molecular Ecology, vol. 23, no. 3, pp. 513-521, 2014.

[50] V. Soria-Carrasco, Z. Gompert, A. A. Comeault et al., "Stick insect genomes reveal natural selection's role in parallel speciation," Science, vol. 344, no. 6185, pp. 738-742, 2014.

[51] L. J. Johnson, P. J. Mill, S. L. Hull, J.-P. Ducrotoy, and K. J. Caley, "Seasonal patterns in the reproductive activity of Barnacle-Dwelling littorinids," Journal of the Marine Biological Association of the United Kingdom, vol. 80, no. 5, pp. 821-826, 2000. 

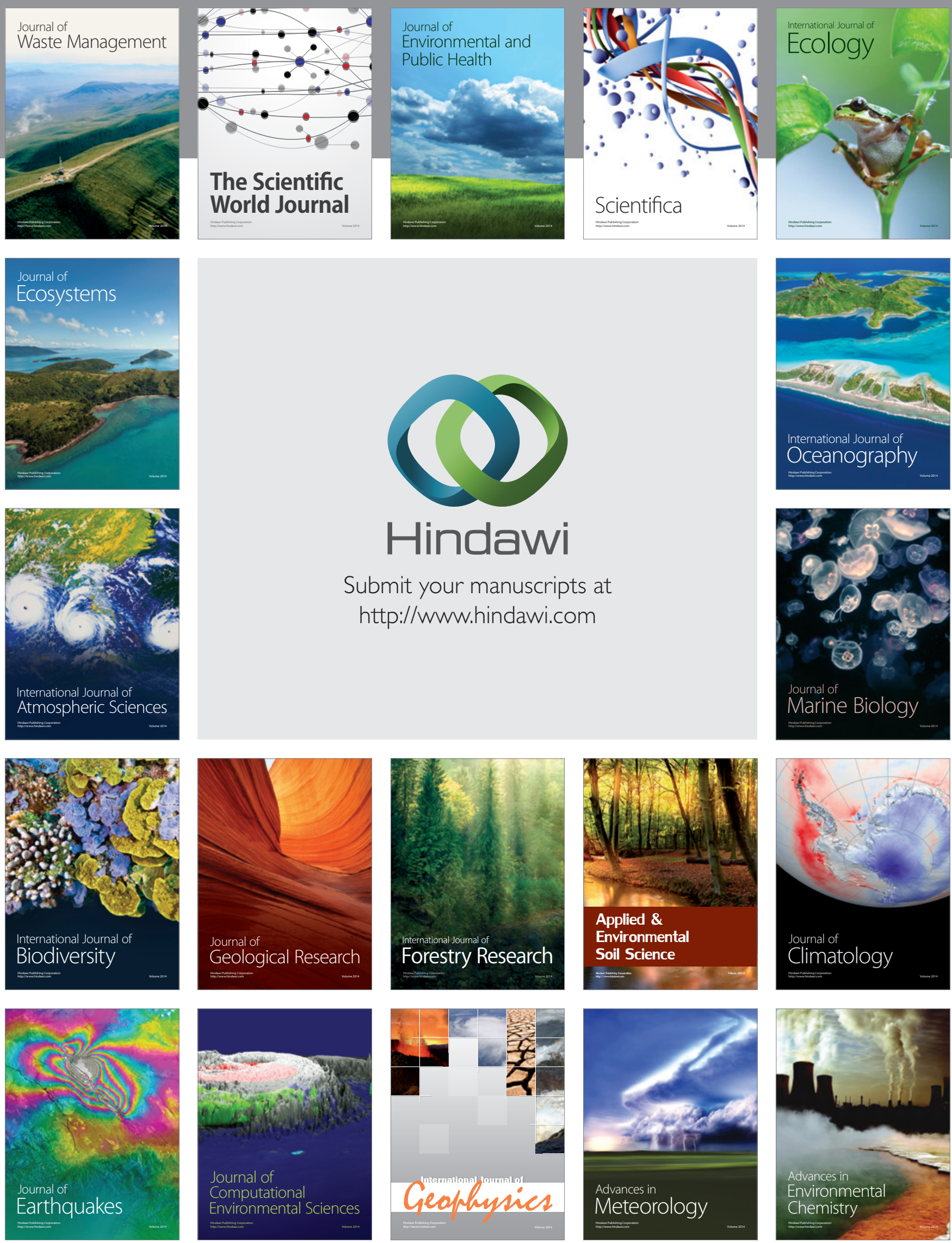